its curve is noteworthy, the eye retaining full vision with no manifest error of refraction.

It is noteworthy that though the inflammation was severe with a good deal of exudate from the posterior surface of the cornea it yet remained localized, suggesting that it was caused by an organism having a limited growth whose course soon came to an end. It will be seen that in these respects the affection of the cornea is similar to that of the skin.

The question arises whether this might be considered as the sole manifestation of herpes of the first branch of the fifth nerve. A resemblance is the late period in which the corneal trouble arose, three weeks after the onset of the varicella; which is a very common time for herpetic affections of the cornea to begin. But there was no pain at any time, very little photophobia; while the rapid and practically complete recovery is very different from herpes. The simplest explanation is that it was a varicella eruption, occurring late because of the special structure of the cornea, a non-vascular and dense tissue which offers special difficulties to the transit of the virus.

\title{
A CASE OF CHLOROSIS WITH OCULAR COMPLICATIONS
}

\author{
BY \\ J. BRUCE Hamilton \\ HOBART
}

IT is an undisputed fact that chlorosis as a disease died with the passing of the 19th century, and according to L. J. Witts ${ }^{4}$ it has almost 'completely disappeared to-day. Its aetiology, and the reason for its disappearance are alike unknown, but Tidy ${ }^{5}$ suggests that its disappearance may be attributed to the improved hygienic life of girls, to whom the disease was almost entirely confined.

The ocular: complications of chlorosis have been occasionally recorded, and Foster-Moore ${ }^{2}$ in 1925 was able to collect in the literature the records of 9 cases; reported between A.D. 1881, and the time of writing. $\therefore$ But a request from me to the Librarian of the Royal Society of Medicine for photostatic copies of reports of all recent cases! of chlorosis with ocular complications has resulted in only one tecord by Brazeau being found. In view of these 'facts I feel it incumbent on 2 me to place on record a further case of chlorosis with 'ocular complications, and after reporting the case fully, $\mathrm{I}$ will make some comments on these complications. 


\section{Case Record}

Mrs. J. B. 33 years of age. Home duties.

December 1, 1933. History. Born in England. Has been living in Australia 14 years. 'Two months ago while travelling in tramcar bumped head-no treatment. Six weeks ago bad pain in right side of head for 4-5 days, followed by double vision. Has never worn giasses. No history of general disability, except loss of weight.

Examination. Right vision, 6/4 and J.1. Left vision, 6/6 and J.2.

Muscle Balance. Distance, $30^{\circ}$ esophoria, $1^{\circ}$ left hyperphoria. Near, $15^{\circ}$ esophoria, $2^{\circ}$ left hyperphoria, no cyclophoria.

Right and left eyes. Slightly limited abduction. Pupils active to light and accommodation. No keratic precipitates. Three dioptres of swelling of both optic discs with complete star figure at each macula. No haemorrhages.

Refraction under mydriatic.

Right

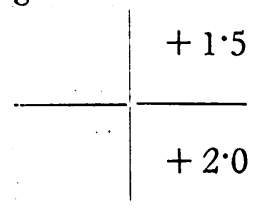

Left

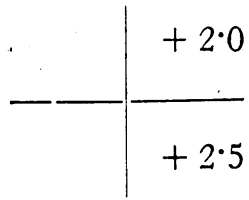

Fields of vision. Right and left.

Form. Normal to 1 degree white, except for slight enlargement of both blind spots.

Colour. Normal to 1 degree red and green.

Diplopia Chart. At 1 metre.

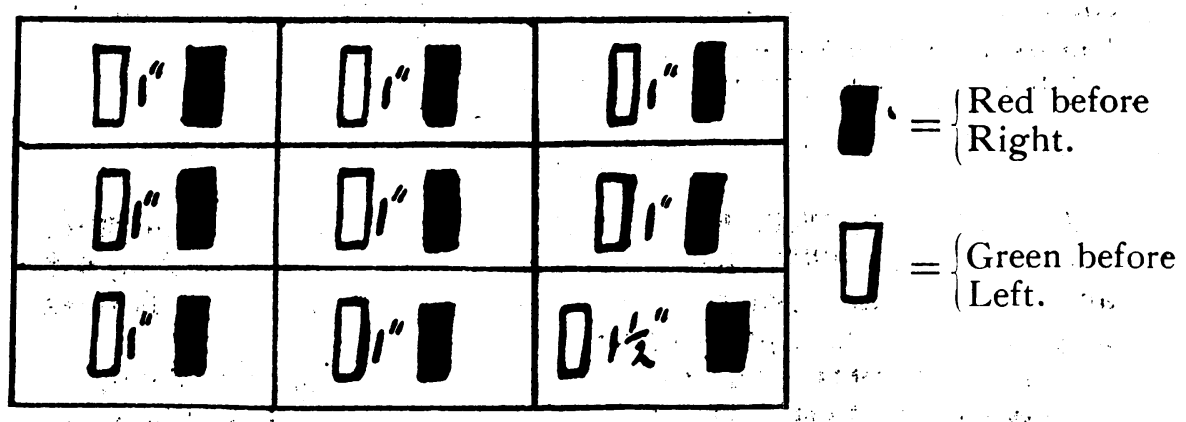

Urine Test. S.g. 1006. Neutral. N.A.Đ.

Blood Count. Report from Dr. Walch :-

Hâemoglobin, 45 per cent.; red cells, 3,510,000 per. c.mm.: colour index, 0.64 ; white cells, $\tau, 500$ per c.mm. 


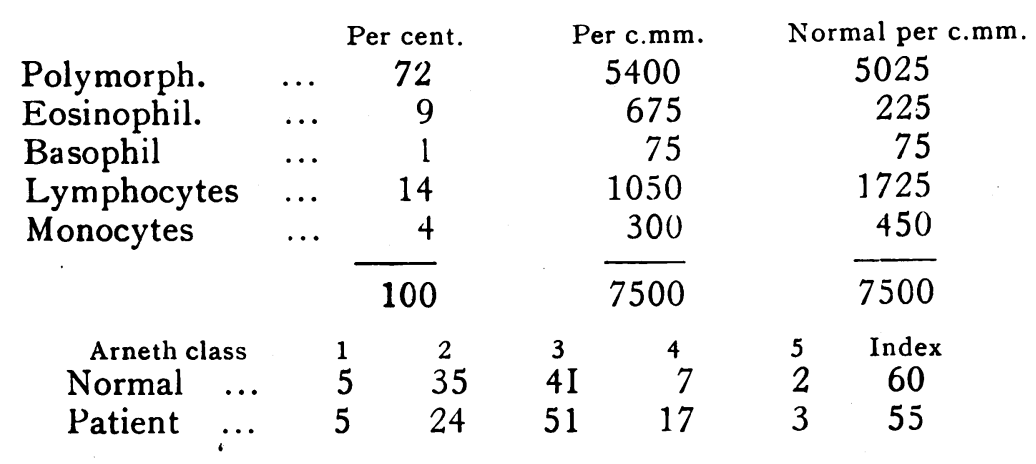

No nucleated red cells seen.

Red cells show slight anisocytosis, but are regular in shape and stain normally.

A marked anaemia of secondary type. The only distinctive feature in the differential count is eosinophilia.

(Signed) J. H. B. Walch.

December 5, 1933.

Blood Test. Report from Dr. Walch.

Wassermann reaction, negative. Kline test, negative.

(Signed) J. H. B. Walch.

December 5, 1933.

December 6, 1933. General examination. Report from Dr. Sprent.

"A stout woman giving a history of previous good health, with normally a sallow complexion. She now shows a characteristic greenish tint underlying her pallor. Her blood picture is not quite characteristic of chlorosis, but she has been taking a tonic containing iron. Chlorosis is uncommon in this country, but she has lived in London until her marriage 14 years ago.

I have given her Bi-Palatinoid Pil. Blaud gr. 10.t.d."

\section{Progress}

December 21, 1933. Dr. Sprent reports :-Haemoglobin 68\%.

December 28, 1933. Right vision, 6/4 and J.1. Left vision, 6/6 and J.2. No diplopia with red green test. Still has 2 dioptres of swelling of the right and left discs.

January 4, 1934. Dr. Sprent reports :-Haemoglobin 80\%.

January 25, 1934. Dr. Sprent reports :-Haemoglobin 90\%. March 7, 1934. Right vision, 6/4 and J.1. Left vision, 6/4 and J.1. Fields of vision. Right and left.

Form. Normal to 1 degree white. No enlargement of blind spots. Right fundus. Optic disc normal. Slight oedema of the macula. 
Left Fundus. Optic disc slightly fuzzy. Remnant of $\frac{1}{2}$ star between disc and macula.

April 6, 1934. Dr. Sprent reports :-Vomiting and headaches have returned. Is losing weight rapidly. Temperature normal. Haemoglobin $100 \%$. Slight fuzziness of both optic discs with a remnant of nasal fan at each macula. Fields of vision. Right and left. Form. Normal to 1 degree white. Right vision, 6/4. Left vision, $6 / 4$.

April 11, 1934. Admitted to hospital with provisional diagnosis of cerebral thrombosis in a blind area. Haemoglobin 100 per cent. $\mathrm{X}$-ray of skull. Negative.

April 23, 1934. Lumbar puncture performed, but no details available, except $R$. of cerebro-spinal fluid was negative.

May 5, 1934. wocharged from hospital.

August 10, 1934. Report from Dr. Sprent. Patient well.

May 21, 1935. History. Lost $2 \frac{1}{2}$ stone in weight last year, but last $5 \mathrm{mf}$ ths has remained stationary. Is still taking tablets regular $1 \%$ Occasional headaches. No further vomiting since lumbar puncture on April 23, 1934. Eye sight good.

Examination. Right vision, 6/4 and J.1. Left vision, 6/4 and J.1. Fundi. Right. Optic disc and macula normal. Left. I isc a little fuzzy nasally. Macula normal. Fields of vision. Right and left. Form. Normal to 1 degree white.

\section{Comment}

This is an undisputed case of chlorosis with compiete recovery of eye signs following iron therapy, and the first feature that asserts itself in the eye signs is the lack of retinal haemorrhage. $\mathrm{Knapp}^{3}$ and Foster-Moore, ${ }^{2}$ both definitely assert that retinal haemorrhages are most unusual in chlorosis. In fact, Knapp quotes Leber as saying that it is questionable whether cases with retinal haemorrhages are true chlorosis. At no period did the patient reported here exhibit the smallest haemorrhage in either fundus.

With regard to the swollen discs, both these authorities quoted above, as well as Brazeau, ${ }^{1}$ stress the fact that kidney disease and cerebral tumour must be excluded definitely and finally, before attributing the oedema of the disc to anaemia. In fact, in Brazeau's case, the provisional diagnosis was cerebral tumour, and was only modified after a marked response to iron. I think that the 18 months follow up in this case without return of swelling excludes both nephritis and cerebral neoplasm, and that the diagnosis of chlorosis is equally confirmed by the rapid decline of the swelling and diplopia, following the administration of iron. 
The cause of the swelling is undoubtedly increased intracranial pressure, as proved by Pagenstecher, and quoted by Knapp. ${ }^{3}$ The result of the lumbar puncture in this patient is unfortunately lacking, except for the Wassermann test, which was negative. But the patient asserts that she has had little or no headaches since the lumbar puncture; which I think is conclusive evidence that the cerebro-spinal fluid was under pressure.

With regard to the ocular palsy. This again is a rare occurrence in chlorosis, but cases with this complication have been recorded. This patient's diplopia rapidly disappeared with the exhibition or iron, and no trace of diplopia could be found 16 days after active treatment was commenced.

In conclusion I should like to acknowledge my indebtedness to Dr. James Walch for his report, and to Dr. James Sprent for his report and progress notes, over a period of 8 months. Also to Dr. Sprent for his comment on reading this proof, that chlorosis is not so dead in Tasmania as supposed, for in the past $8 y$ ears he has seen 6 cases of undoubted chlorosis in Hobart.

\section{Summary}

1. A case of chlorosis with ocular complications is reporteci.

2. Three dioptres of papilloedema was found in each eye.

3. All eye signs disappeared after intensive iron therapy.

4. The patient has been well and free from eye signs for 12 months.

\section{REFERENCES}

1. Brazeau, G. N.-“"Neuropapilloedema in Chlorosis." Amer. Jl. of Ophthal., Vol. VIII, pp. 811-812, 1925.

2. Foster-Moore, R.-Medical Ophthalmology. 2nd Edition. 1925.

3. Knapp, Arnold.-Medical Ophthalmology.

4. Price, F. W.-Text-book of the Practice of Medicine. 4th Edition. 1933.

5. Tidy, H. L.-Synopsis of Medicine. 6th Edition. 1934.

\section{TREMULOUS LENS}

BY

A. W. D'Ombrain, D.O.M.S(Lond.)

WEST MAITLAND, AUSTRALIA

A MAN aged 50 years was found to have an almost mature cataract in the right eye. The left eye was hypermetropic and with correction read 6/6. A month later the cataractous right eye developed irido-cyclitis. Atrophy, in patches, of the pigment layer of the iris was made out with the corneal microscope; also there were 